\title{
THE SEASONAL ABUNDANCE OF THE NEWLY ESTABLISHED PARASITOID COMPLEX OF THE EUCALYPTUS TORTOISE BEETLE (PAROPSIS CHARYBDIS)
}

\author{
D.C. JONES and T.M. WITHERS \\ Forest Research, PB 3020, Rotorua \\ Corresponding author:diane.jones@forestresearch.co.nz
}

\begin{abstract}
Enoggera nassaui has been the key biological control agent of the eucalyptus tortoise beetle Paropsis charybdis since 1987. In 2001 a second egg parasitoid Neopolycystus insectifurax as well as an obligate hyperparasitoid of E. nassaui, Baeoanusia albifunicle were detected in New Zealand. Monitoring of Eucalyptus nitens plantations in the central North Island revealed that $50 \%$ of $P$. charybdis eggs in half the sites were parasitised by E. nassaui in early summer. However, later in the season this was followed by a reduction to $10 \%$ parasitism by E. nassaui, the remaining $40 \%$ of parasitised eggs being hyperparasitised by $B$. albifunicle. Neopolycystus insectifurax parasitised an additional 35-100\% of eggs in late summer. This indicates that, while B. albifunicle has the potential to severely reduce the effectiveness of $E$. nassaui, the new agent $N$. insectifurax is a promising alternative.
\end{abstract}

Keywords: biological control, egg parasitoid, Baeoanusia albifunicle, Neopolycystus insectifurax, Paropsis charybdis.

\section{INTRODUCTION}

The Eucalyptus tortoise beetle, Paropsis charybdis Stål (Coleoptera: Chrysomelidae), is a pest of Eucalyptus plantations. Enoggera nassaui (Girault) (Hymenoptera: Pteromalidae), an egg parasitioid, was introduced from Western Australia in 1987 as a biological control agent (Bain \& Kay 1989) and initially had success in suppressing $P$. charybdis populations (Kay 1990). However, to improve biological control effectiveness in colder sites another population of $E$. nassaui from a colder climatic origin (Tasmania) was released in the central North Island in 2000.

In 2001 two new Australian parasitoids of $P$. charybdis were detected in New Zealand (Murphy 2002). These were the parasitoid Neopolycystus insectifurax Girault (Hymenoptera: Pteromalidae) and an obligate (Tribe 2000) hyperparasitoid of Enoggera sp., Baeoanusia albifunicle Girault (Hymenopetra: Encrytidae). At one site over half the egg batches parasitised by E. nassaui also contained the hyperparasitoid (B.D. Murphy, pers. comm.). It is feared this hyperparasitoid is disrupting the biological control of $P$. charybdis by E. nassaui. Neopolycystus insectifurax was originally released as a potential biological control in New Zealand in 1987 along with E. nassaui, but failed to establish (Bain \& Kay 1989). Berry (2003) has determined that the recent occurrence of $N$. insectifurax is the result of a separate and probably accidental selfintroduction rather than from those released in 1987. It is hoped that $N$. insectifurax could assist with the biological control of P. charybdis as species of Neopolycystus are not hyperparasitised by B. albifunicle (Tribe 2000). Because of this $N$. insectifurax was mass reared and released in the central North Island over the 2002/2003 summer, in an attempt to increase its distribution. 
This paper reassesses the status of $P$. charybdis biological control following these new incursions by measuring the seasonal occurrence of the three species, E. nassaui, $B$. albifunicle and $N$. insectifurax, in parasitised $P$. charybdis eggs in the North Island.

\section{METHODS}

Four 2-3-year-old E. nitens plantations in the central North Island were monitored between October 2002 and April 2003 for the presence of P. charybdis, E. nassaui, $N$. insectifurax and $B$. albifunicle. The study areas spanned a range of altitudes and micro-climates, Haumingi (Lake Rotoiti, $38^{\circ} 03^{\prime} \mathrm{S}, 176^{\circ} 27^{\prime} \mathrm{E}$ ), Rotomahana (Lake Tarawera, $38^{\circ} 05^{\prime} \mathrm{S}, 176^{\circ} 41^{\prime} \mathrm{E}$ ) and Seven Oaks (north of Lake Taupo, 38 $36^{\circ} \mathrm{S}$, $175^{\circ} 56^{\prime} \mathrm{E}$ ). A fourth site approximately $30 \mathrm{~km}$ south of Rotorua (Murphys, $38^{\circ} 20^{\prime} \mathrm{S}$, $176^{\circ} 25^{\prime} \mathrm{E}$ ) was added to the sampling regime in December when insecticide was sprayed at Seven Oaks. At each site, 10 trees were randomly selected and branches bearing flushing adult foliage were either cut from the tree or inspected from the ground each week for the presence of $P$. charybdis eggs.

Field-collected eggs were stored in separate vials in a laboratory at $20^{\circ} \mathrm{C}(14: 10 \mathrm{~h}$ light:dark photoperiod) until eclosion. The total number of eggs, and larvae, parasitoids and hyperparasitoids that emerged from each sample were recorded three times a week. Egg parasitism and egg hyperparasitism were determined as a percentage of the total monthly eggs collected at each site. Eggs were assumed to have had significant exposure to parasitism before collection and therefore all eggs collected were included in the analysis.

\section{Paropsis charybdis egg numbers}

\section{RESULTS}

The number of $P$. charybdis eggs collected each week was highly variable (Fig. 1). Egg abundance peaked in all sites between mid November and late December, except at Haumingi, where a peak did not occur until February. The Seven Oaks site was sprayed with the organophosphate insecticide 'Dominex' (active ingredient alpha-cypermethrin at $300 \mathrm{ml} / \mathrm{ha}$ ) in late December and the Murphys site was sprayed with the organophosphate insecticide 'Fastrac' (active ingredient alpha-cypermethrin at $300 \mathrm{ml} / \mathrm{ha}$ ) in early February to reduce the damage from P. charybdis. Egg numbers subsequently declined rapidly at Seven Oaks and no eggs were detected for the rest of the season. At Murphys no subsequent decline in egg numbers occurred, suggesting that the insecticide was ineffective. In the remaining two unsprayed sites, a peak of P. charybdis egg abundance occurred in February (Fig. 1).

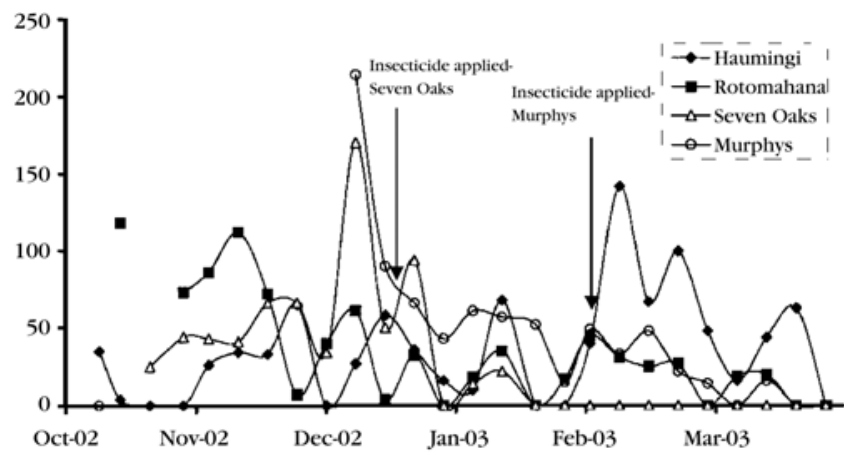

FIGURE 1: Total Paropsis charybdis egg abundance at four sites in the Central North Island. 


\section{Egg parasitism}

Egg parasitism by E. nassaui differed between sites, being non-existent at Rotomahana prior to December, and low $(<7 \%)$ at Haumingi and Seven Oaks. Parasitism by E. nassaui generally peaked in December (17-50\%) at all sites. At the Rotomahana site the highest parasitism occurred in February (Fig. 2).

Enoggera nassaui suffered hyperparasitism from $B$. albifunicle at all sites except for Seven Oaks (Lake Taupo). Baeoanusia albifunicle was occasionally detected at Haumingi (Fig. 2a) and Rotomahana (Fig. 2b), where it parasitised a variable portion of eggs (10-20\%) throughout the season. At Murphys (Fig. 2d), the hyperparasitoid was present in all months and as the season progressed it hyperparasitised an increasing portion of E. nassaui-parasitised eggs. By March, B. albifunicle had effectively destroyed all parasitism by $E$. nassaui at this site by attacking $100 \%$ of parasitised eggs.

Neopolycystus insectifurax was detected in November and December at Haumingi and Murphys, where it parasitised $0.3-15 \%$ of eggs (Fig. 2a \& 2d). In mid December, 650 laboratory reared $N$. insectifurax were released at both Haumingi and another site where it had previously not been recorded, Rotomahana. This species was subsequently recorded abundantly in samples at both release sites; for instance in March parasitism reached $86 \%$ of all eggs at Haumingi (Fig. 2a) and 100\% of eggs at Rotomahana (Fig. 2b).

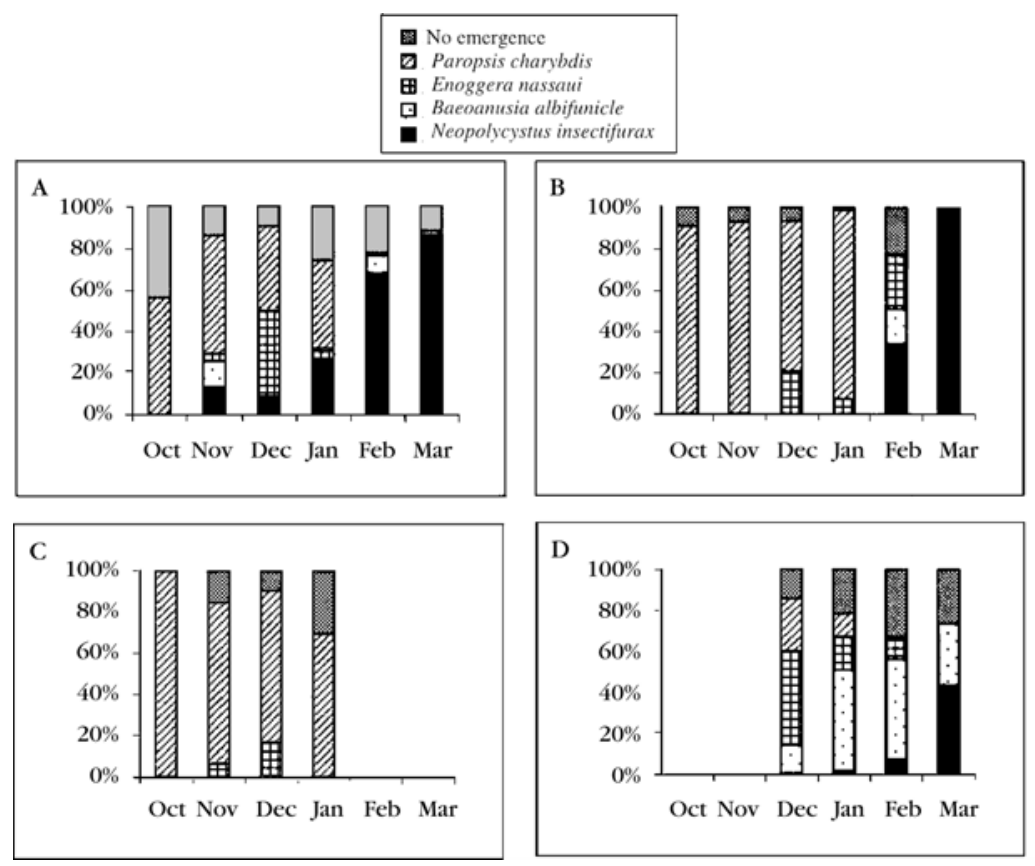

FIGURE 2: The mean rates of emergence (\%) of Paropsis charybdis, Enoggera nassaui, Neopolycystus insectifurax and Baeoanusia albifunicle from collected $P$. charybdis eggs during 2002-2003. (a) Haumingi, (b) Rotomahana, (c) Seven Oaks and (d) Murphys. 


\section{DISCUSSION}

In New Zealand, $P$. charybdis has two generations each summer. Overwintered adults emerge in spring and start ovipositing in October. The time from oviposition to adult eclosion is 7-9 weeks (Styles 1970). Hence the December peak in eggs follows the emergence of first generation adults. A second peak in eggs occurs in February following the emergence of second generation adults (Stevens 1973; Kay 1990; Murphy 1998). Murphy \& Kay (2000) also found this same trend when they monitored $P$. charybdis populations from 1997-1998 using frass collection.

In previous studies, when $E$. nassaui was the only natural enemy effective against P. charybdis in New Zealand (Murphy 1998), E. nassaui induced low parasitism of $P$. charybdis eggs early in the season. This was thought to be due to high overwintering mortality of E. nassaui. By March however, good control of the $P$. charybdis population was generally achieved with at least $80 \%$ egg parasitism (Murphy \& Kay 2000). Although there is only one season of data with which to compare the present complex of parasitoids to the earlier situation, some significant changes are evident. In the present study the early season trend of low parasitism by E. nassaui was identical. However, in 2003 by late season (March) all eggs that had been parasitised by E. nassaui were subsequently hyperparasitised by $B$. albifunicle. This large reduction in egg parasitism by $E$. nassaui in the second peak of $P$. charybdis egglaying is highly significant in terms of biological control of $P$. charybdis.

Hence in sites where $B$. albifunicle is present the abundance of E. nassaui has been severely reduced. However, hyperparasitism of parasitised eggs by $B$. albifunicle does still prevent $P$. charybdis eggs from hatching. So it is postulated that the only disruptive effect of $B$. albifunicle is the increased mortality, which will reduce the rate of population increase of $E$. nassaui. Overwintering survival of $E$. nassaui was already thought to be the factor limiting its effectiveness as a biocontrol agent, and this may now be further exacerbated by the hyperparasitism it is experiencing. The importance of both these factors requires further investigation.

The presence of $N$. insectifurax at three of our study sites as well as it not being hyperparasitised by $B$. albifunicle (Tribe 2000), suggest $N$. insectifurax has potential as an effective agent against $P$. charybdis. Neopolycystus insectifurax was first detected in November, though there was increasing parasitism as the season progressed towards autumn. No $N$. insectifurax were released at Murphys or within $35 \mathrm{~km}$ of this site, so the results may be indicative of a naturally occurring population of $N$. insectifurax in this region. The mean rate of parasitism increased from less than $1 \%$ in December through to $44 \%$ in March. Even more promising than this was the $100 \%$ parasitism N. insectifurax achieved late in the season in the eggs laid by the second generation of adults at Rotomahana. Because of the high parasitism rates achieved at this and the Haumingi site it is thought that the mass-rearing and release of $N$. insectifurax was worthwhile. It appears that $N$. insectifurax has the potential to control the eggs laid by the second generation of $P$. charybdis adults as it achieved $>80 \%$ parasitism. In previous years E. nassaui attacked these eggs, but now that this species has been hyperparasitised, $N$. insectifurax will instead fulfil this function.

\section{CONCLUSION}

Effective biological control of $P$. charybdis in New Zealand was in doubt because of significant hyperparasitism of $E$. nassaui by B. albifunicle. It is likely that the abundance of this previously useful egg parasitoid will decrease and the self-introduced $N$. insectifurax will become more abundant, since the latter remains free from hyperparasitism. Further rearing and release of $N$. insectifurax, especially in the sites where $B$. albifunicle is found, is recommended in order to assure the establishment of $N$. insectifurax and continued control of P. charybdis.

\section{ACKNOWLEDGEMENTS}

We are grateful to Brendan Murphy for insect identification and to GSL Capital Ltd and Hardwood Management Ltd for access to sampling sites. This research was funded by FRST subcontract CO4X04 to Forest Research. 


\section{REFERENCES}

Bain, J.; Kay, M.K. 1989: Paropsis charybdis Stål, eucalyptus tortoise beetle (Coleoptera: Chrysomelidae) In: Cameron, P.J.; Hill, R.L.; Bain, J.; Thomas, W.P., ed. A review of biological control of invertebrate pests and weeds in New Zealand 1874-1987. CAB International Publishers, Wallingford, Oxon, UK. Pp. 281-287

Berry, J.A. 2003: Neopolycystus insectifurax Girault (Hymenoptera: Pteromalidae) is established in New Zealand, but how did it get here? N.Z. Entomol.: in press

Kay, M. 1990: Success with biological control of the Eucalyptus tortoise beetle, Paropsis charybdis. What's New in Forest Research No. 184, New Zealand Forest Research Institute, Rotorua. 4 p.

Murphy, B.D. 1998: Effectiveness of Enoggera nassaui Girault as a biological control agent of Paropsis charybdis Stål. Masters thesis, University of Waikato, New Zealand. $90 \mathrm{p}$.

Murphy, B.D.; Kay, M.K. 2000: Paropsis charybdis defoliation of Eucalyptus stands in New Zealand's Central North Island. N.Z. Plant Prot. 53: 334-338.

Murphy, B. 2002: New insect threatens control of Eucalyptus tortoise beetle. Forest Health News 117: 3. New Zealand Forest Research Institute Limited, Rotorua, New Zealand.

Stevens, D. 1973: The host plant relationships of Paropsis charybdis Stål (Coleoptera: Chrysomelidae). PhD Thesis, University of Canterbury, New Zealand.

Styles, J.H. 1970: Notes on the biology of Paropsis charybdis Stål (Coleoptera: Chrysomelidae). N.Z. Entomol. 4: 102-111.

Tribe, G.D. 2000: Ecology, distribution and natural enemies of the Eucalyptus-defoliating tortoise beetle Trachymela tincticollis (Blackburn) (Chrysomelidae: Chrysomelini: Paropsina) in southwestern Australia, with reference to its biological control in South Africa. Afr. Entomol. 8: 23-45. 